\title{
EL ABP COMO DISEÑO INSTRUCCIONAL PARA LABORATORIOS VIRTUALES EN PSICOLOGÍA
}

\author{
Guarneros Reyes Esperanza, Maldonado Enríquez Osmar, Silva Rodríguez Arturo \\ FES Iztacala, UNAM \\ México
}

\begin{abstract}
RESUMEN
Existen laboratorios de investigación básica o aplicada, los más conocidos presenciales, pero existen otros virtuales que permiten comprobar teorías con demostraciones virtuales. En la enseñanza es necesaria la práctica y simulación de aprendizajes que requieren los profesionales de psicología para el ámbito aplicado, de este escenario, el objetivo de artículo fue diseñar un laboratorio virtual en psicología a través de un diseño instruccional basado en el Aprendizaje Basado en Problemas ABP, para que los estudiantes de psicología desarrollen habilidades y amplíen su repertorio de competencias, para sobre cómo evoluciona el lenguaje y problemas del habla como dislalias. para estudiantes de psicología de sistema en línea de la UNAM y profesionales relacionados al ámbito infantil. Se describe el proceso de diseño y se presentan resultados sobre el funcionamiento del laboratorio virtual en un grupo piloto de 203 participantes. Los resultados muestran que es un entorno de aprendizaje simulado el cual pone en práctica habilidades que desarrolla el ABP.
\end{abstract}

Palabras Clave:

laboratorios virtuales de enseñanza, ABP, estudiantes universitarios, enseñanza de la psicología, diseño de ambientes virtuales de aprendizaje.

\section{THE PBL AS AN INSTRUCTIONAL DESIGN FOR VIRTUAL LABORATORIES IN PSYCHOLOGY}

\begin{abstract}
There are laboratories of basic or applied research, the most well-known presence, but there are other virtual ones that allow to verify theories with virtual demonstrations. In teaching it is necessary the practice and simulation of learning required by psychology professionals for the applied field, from this need, this article aimed to design a virtual laboratory in psychology through the instructional design based on the PBL model, allowing develop skills and expand the repertoire of competencies of psychology students to confront problems and take a better decision in the applied field, in this case on children's language skills and speech problems such as dyslalia. The development of the proposal is based on the virtual laboratory created for UNAM online psychology students and professionals related to the children field. The design process is described and results are presented on the operation of the virtual laboratory in a pilot group of 203 participants. The results show that it is a simulated learning environment which puts into practice the skills developed by the PBL.
\end{abstract}

Keywords:

virtual teaching laboratories, PBL, university students, teaching psychology, design of virtual learning environments

Bitácora del Artículo:

| Recibido: 1 de febrero de 2017 | Aceptado: 2 marzo de 2017 | Publicado en línea: enero-junio de 2017 | 
Innovación y desarrollo tecnológico | E[ ABP como diseño insturccional ... | Guarneros-Reyes, Maldonado-Enríquez \&Z Silva-Rodríguez

\title{
EL ABP COMO DISEÑO INSTRUCCIONAL PARA LABORATORIOS VIRTUALES EN PSICOLOGÍA
}

\author{
Guarneros Reyes Esperanza, Maldonado Enríquez Osmar, Silva Rodríguez Arturo
}

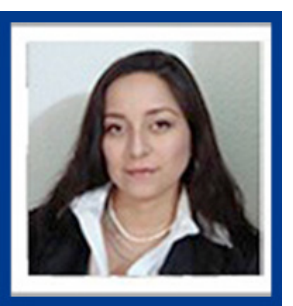

Esperanza Guarneros Reyes

FES Iztacala UNAM

Correo: esperanzagr@gmail.com

Profesora de Carrera Asociada C Tiempo Completo de la Licenciatura de psicología en SUAyED y de la Maestría en Psicología en la FES Iztacala, UNAM. Pertenece al SNI. Responsable del Laboratorio Digital de Desarrollo Infantil LDDI de la FES Iztacala. Doctora en Psicología por la Facultad de Psicología UNAM, Ver más...

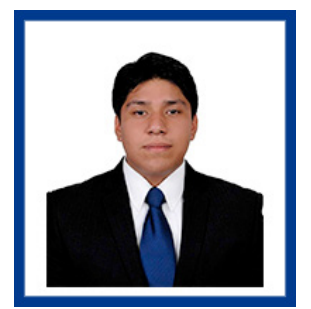

Osmar Maldonado Enríquez FES Iztacala UNAM

Correo: osmaen.psic@gmail.com

Licenciado en Psicología por la Facultad de Estudios Superiores Iztacala, UNAM. Ha participado en la organización de eventos académicos para la promoción de la cultura y la ciencia, experiencia en el ámbito educativo, en la evaluación en el ámbito infantil y adolescente, en el diseño de programas de intervención educativa y en el diseño de laboratorios virtuales. Ver más...

\section{CONTRIBUCIÓN DE LOS AutORES}

A Esperanza Guarneros se le atribuye la ideación del laboratorio virtual, su diseño, construcción y la capacitación a los participantes. I Osmar Maldonado participó como alumno becario para titulación en el proyecto, capacitándose en el diseño de ambientes virtuales por ABP| Arturo Silva participó capacitando a los colaboradores y alumnos participantes del proyecto en la metodología del ABP.

\section{AgRADECIMIENTOS}

Este artículo se realizó gracias al financiamiento proporcionado por el programa PAPIME PE306416 Enseñanza mediante un simulador digital de habilidades profesionales en alumnos de psicología para tratar las dislalias y PAPIME PE307717 Diseño de simuladores en Moodle para la enseñanza de la manera en que evoluciona el lenguaje infantil.

\section{Datos de Filiación de los Autores}

Facultad de Estudios Superiores Iztacala, UNAM.

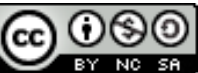

Copyright: @ 2017 Guarneros-Reyes E., Maldonado-Enríquez, O. \& Silva-Rodríguez, A.

Este es un artículo de acceso abierto distribuido bajo los términos de la licencia Creative Commons Reconocimiento-NoComercial-Compartirlgual 4.0 Internacional, por lo que su contenido gráfico y escrito se puede compartir, copiar y redistribuir total o parcialmente sin necesidad de permiso expreso de sus autoras con la única condición de que no se puede usar con fines directamente comerciales y los términos legales de cualquier trabajo derivado deben ser los mismos que se expresan en la presente declaración. La única condición es que se cite la fuente con referencia a la Revista Digital Internacional de Psicología y Ciencia Social y a sus autoras. 


\section{TABLA DE CONTENIDO}

INTRODUCCIÓN

Naturaleza y contexto de la innovación, 21

Características del Laboratorio virtual de enseñanza, 23

Aprendizaje basado en problemas ABP como diseño instruccional, 23

Procedimiento de creación del Laboratorio virtual de enseñanza con

ABP, 24

Composición del Laboratorio virtual de enseñanza, 24

Rango de aplicación de la innovación, 26

FUNCIONAMIENTO DE LA INNOVACIÓN

Características de los participantes, 26

Resultados del funcionamiento del Laboratorio virtual, 18

Registro de actividad, 18

Evaluación del usuario acerca del Laboratorio virtual , 19

Discusión

CONCLUSIONES

REFERENCIAS

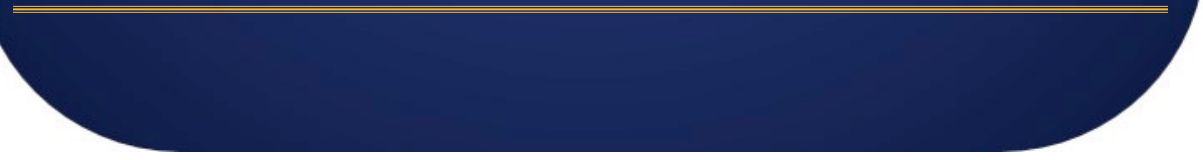




\section{INTRODUCCIÓN}

\section{Naturaleza y contexto de la innovación}

U n laboratorio es un lugar físico dotado de los medios necesarios - como instrumentos o equipo de laboratorio - para realizar investigaciones, experimentos, prácticas y trabajos de carácter científico, tecnológico o técnico, según la rama de la ciencia a la que se dedique. También puede ser un aula o dependencia de cualquier centro docente, diseñada de modo que sea posible desarrollar y complementar prácticas y trabajos en relación con la enseñanza y el aprendizaje, permitiendo al estudiante desarrollar habilidades manipulativas y de medición, además de la aplicación de distintas teorías (Cardona, 2013).

Los laboratorios se han desarrollado según dos objetivos: de investigación y de enseñanza. La importancia de los laboratorios de investigación o experimentación, y en cualquiera de sus especialidades —como química, investigación clínica, física o biología-, radica en el hecho de que las condiciones ambientales son controladas y normalizadas, de modo que en ellos se asegura que no se produzcan influencias extrañas a las conocidas o previstas, que alteren el resultado del experimento o medición, es decir, hay control experimental, y se garantiza que el experimento o medición se puede repetir en cualquier laboratorio obteniendo el mismo resultado, esto es, existe normalización. Los laboratorios de investigación son espacios diseñados para contener equipo especializado y altamente sofisticado para realizar actividades de investigación; en estos espacios se realizan actividades de experimentación y evaluación, generando nuevos hallazgos, conocimientos e innovación científica, académica, social, cultural o industrial (Flores, Sahelices y Moreira, 2016).

Los laboratorios de enseñanza, son definidos como espacios que se han enfocado en que los estudiantes aprendan los principios básicos y los procesos aplicados de la ciencia, mediante la guía de un profesor. La instrucción del laboratorio les permite participar en experiencias prácticas y de auténtico descubrimiento, desarrollando estudios científicos y habilidades investigativas (Cornell University Center for Teaching, 2017). Al estar en contacto directo con las experiencias prácticas, el aprendizaje se torna vivencial por la posibilidad de manipular la realizad que expresan los libros. En el caso específico de la práctica psicológica, dentro de los laboratorios ha sido por excelen- cia un modelo presencial en el que hay espacios físicos, mesas, cajas de Skinner, cabinas, laberintos y cámaras de Gesell para que los estudiantes realicen estudios, desarroIlando las habilidades manipulativas, de medición y aplicación de distintas teorías (Cardona, 2013).

En el área de investigación en la carrera de Psicología realizada de esta manera, toma tiempo y un lugar específico acondicionado; se requiere instrumental especializado, animales criados en condiciones especiales $y$, aunque es requisito contar con laboratorios para poder impartir un programa de psicología en las universidades mexicanas, no necesariamente se utilizan para la función que fueron destinados. En el caso de la carrera de psicología en línea impartida en México, se cuenta con la plataforma educativa donde sus contenidos en la mayor parte son textos - como capítulos de libro, artículos, presentaciones, manuales y antologías-; en algunos casos videos. Los estudiantes de psicología en línea no tienen la oportunidad de navegar en entornos variados para aprender acerca de los principios científicos y mucho menos los aplicados de su carrera; por ejemplo, los laboratorios virtuales pueden contener simulaciones de problemáticas donde ellos podrían poner a prueba un programa basados en los hallazgos de la investigación y poder ver los probables efectos.

Debido a esto, es necesario implementar nuevas herramientas y así innovar la manera de enseñanza de la práctica psicológica, como ya se ha hecho en otros niveles educativos y ciencias; por ejemplo, para enseñar a estudiantes de secundaria algunos de los procesos químicos, a través de la simulación en un laboratorio virtual con la finalidad de apoyar las clases, extendiendo el alcance del aprendizaje de los estudiantes, al experimentar en los laboratorios virtuales con problemas reales y llevar a cabo soluciones en un tiempo relativamente corto (Griffiths, 2013). En el caso de la práctica en los ambientes virtuales de laboratorio, permitiría a los estudiantes contar con escenarios de práctica simulada donde podrían enfrentarse con problemas comunes que atiende el psicólogo mediante escenarios de aprendizaje virtual. En sí, los laboratorios virtuales de enseñanza pueden enriquecer la educación presencial y, sobre todo, la educación a distancia, fortaleciendo los aprendizajes.

La creación de estas innovaciones tecnológicas conllevan cambios en los roles de los estudiantes y los profesores que participan en el proceso de aprendizaje (Faúndez, Bravo, Melo y Astudillo, 2014; Rivera, Agudelo, Ramos y Vargas, 2015). Dichos roles requieren que los estudiantes manejen herramientas multimedia interactivas, elementos de red, hardware y aplicaciones de software que simulan procesos de la vida cotidiana e instrumentos que permiten medir la forma en que evolucio- 
nan las dimensiones de dichos procesos. En el caso de los profesores, se requiere que diseñen entornos de aprendizaje virtuales, enriquecidos mediante plataformas de aprendizaje, recursos multimedia, diseño gráfico y juegos interactivos, entre otros. Asimismo, los laboratorios virtuales de enseñanza generan nuevos contextos libres de las restricciones que imponen el tiempo y el espacio en la enseñanza presencial, con lo que los estudiantes pueden entrar a ellos en cualquier momento que lo necesiten (Faúndez, Bravo, Melo y Astudillo, 2014).

Una ventaja más de los laboratorios virtuales es que no dependen necesariamente de un docente que proporcione un método para lograr el proceso de aprendizaje; los laboratorios se pueden programar para guiar al estudiante a alcanzar los objetivos de aprendizaje e interactuar en diversas actividades o ejercicios. Sus características básicas son una interfaz de usuario intuitiva y fácil de usar, una instrumentación simulada interactiva que posea una función similar a la de los instrumentos reales, pues relacionan los conceptos teóricos con los prácticos mediante actividades y experimentos, los cuales ocupan poca memoria, logrando así integrarse en cualquier aplicación informática; si se realizan experimentos destructivos o dañinos, es posible prever consecuencias para evitarlas o prevenirlas en los escenarios reales, contribuyendo a evitar daño en los sujetos participantes - tanto humanos como infrahumanos - (Meneces y Ordosgoitia, 2009).

Mediante estos sistemas de aprendizaje virtual se pueden realizar cuatro procedimientos principalmente: 1) acelerar el proceso de aprendizaje; 2) facilitar el acceso al mismo; 3) personalizar el aprendizaje, y 4) proporcionar un entorno educativo más completo (Griol, Sanchis, Molina y Callejas, 2014).

La implementación de los laboratorios virtuales de enseñanza pueden traer consigo un cambio en la manera de aprender, pues, pese a que son simulaciones de computadora, las habilidades y destrezas (como resolución de problemas específicos, pensamiento crítico, toma de decisiones, capacidad de búsqueda y análisis de información, mayor motivación, aprendizaje más significativo, desarrollo de habilidades de aprendizaje, elaboración de un modelo propio de trabajo, integrar el conocimiento obtenido y mayor responsabilidad de su aprendizaje), además ofrecen realizar experimentos en menos tiempo y reproducir los procesos cuantas veces sea necesario, programando diferentes parámetros obteniendo diversos resultados. Esto es posible dependiendo del objetivo y metodología que subyace en el laboratorio virtual.

Algunos de estos laboratorios se han desarrollado principalmente en Europa y Latinoamérica; en México se ha encontrado tecnologías similares. Los casos encontrados son:

1. Labpsico de España, laboratorio virtual creado en 2002 por un grupo de jóvenes estudiantes de psi- cología de la universidad de Deusto, donde se realizan distintos experimentos de índole psicológica (http://www.labpsico.deusto.es/) (Matute, Goikoetxea, Blanco, Moreno, Martínez y Díaz, 2017).

2. VlabQ, ChemLab y LiveChem, en los que los participantes simulan procesos químicos (Vázquez, 2009).

3. En el Laboratorio Virtual de la Universidad Politécnica de Madrid se realizan prácticas virtuales simuladas, experiencias con materiales peligrosos sobre ingeniería, física, química, electrónica y arquitectura (http://3dlabs.upm.es/) (Universidad Politécnica de Madrid, 2017).

4. El laboratorio de enseñanza virtual y ciberpsicología en México, donde se brinda servicio psicológico en línea (http://fundacionunam.org.mx/humanidades/ciberpsicologia/) (Hoyos, López, Maldonado, Esquivel y Villalobos, 2015).

5. El Laboratorio de Psicología Computacional (LabPsiCom), que es un laboratorio virtual portugués y trabaja el uso de aplicaciones de tecnologías de la información en el campo de la psicología, como fobias, atención y memoria (http://labpsicom.ulusofona.pt/) (Gamito, Oliveira, Baptista, Morais, Lopes, Rosa y Santos, 2014).

6. Espacio virtual dirigido a la enseñanza de procesos psicológicos básicos y aplicados, en este caso respecto a los principios del condicionamiento operante y clásico, por medio de un laboratorio virtual, donde se practicaron dichos principios mediante la simulación de una rata virtual (Lewis, 2015).

7. Laboratorios de física, que están diseñados para comprobar teorías y donde además se realizan experimentos que lo ilustren. Algunos de ellos son Interactive Physic (http://www.design-simulation.com/ip/), Phet (https://phet.colorado.edu/es/) de la Universidad de Colorado y Orbit Xplorer (http://www.ottisoft.com/ orbit_x.htm); todos eatán basados en simulaciones que demuestran leyes científicas, como los de simulación de procesos biológicos (Vázquez, 2009).

Los laboratorios virtuales representan una gran herramienta en cuanto al ahorro de tiempo y costos, siendo innecesario comprar sujetos infrahumanos experimentales, beneficiando al medio ambiente con bajo impacto ecológico, o espacios físicos o materiales de laboratorio para llevar efectuar las prácticas o experimentos; aunado a esto, los escenarios virtuales facilitan a los estudiantes simulaciones de problemas, con los cuales pueden practicar las veces que sea necesario para desarrollar habilidades cognitivas e interpersonales al simular diversas situaciones, las cuales no siempre pueden ser recreadas en un laboratorio presencial. Los 
laboratorios virtuales de psicología que existen se enfocan sobre todo a la investigación, o son utilizados en el proceso terapéutico de trastornos psicológicos, que no necesariamente son laboratorios, sino recursos tecnológicos para la atención psicológica asistida con tecnología; en ese sentido, los usuarios son pacientes o sujetos que participan en la investigación. Otro objetivo que pueden tener los laboratorios virtuales es la formación, la enseñanza y el aprendizaje, como el caso de los creados para demostrar las leyes de la física o las simulaciones de fórmulas químicas o procedimientos médicos. En España, la Universidad de Alicante ha propuesto una metodología de enseñanza donde se utiliza esta herramienta virtual en actividades teóricas y prácticas, como robótica, electromecánica y sistemas de percepción y control automático (Pomares, Candelas, García, Gil, Jara, Puente, Torres, Mira y Pérez, 2014).

Los laboratorios de psicología para la enseñanza de procesos aplicados y de manera virtual, han sido escasamente explorados; las posibilidades en carreras de psicología a distancia son amplias, porque pueden brindar experiencias más próximas a la realidad psicológica que enfrentaran los estudiantes. Asimismo, los laboratorios virtuales enfocados a la enseñanza pueden brindar a los estudiantes la posibilidad de simular las teorías, pero también la recreación de problemas que deben solucionar, explorando soluciones posibles y comprendiendo mejor algunas consecuencias o efectos de las acciones e intervenciones que pueden implementar; este escenario rico de aprendizaje es posible si el laboratorio se guía con una metodología apropiada que le permita ser un entorno virtual óptimo; por tal motivo, el objetivo de este artículo es presentar como propuesta un laboratorio virtual de psicología diseñado mediante el modelo de Aprendizaje Basado en Problemas (ABP) para la enseñanza de procesos psicológicos aplicados, el caso específico del estudio del lenguaje infantil, las habilidades lingüísticas de niños en preescolar y sus problemas.

\section{Características del Laboratorio Virtual de Enseñanza}

El Laboratorio Virtual de Enseñanza fue diseñado con tecnologías de acceso libre en Moodle 2.9; Moodle fue la opción por su facilidad de actualización y compatibilidad por ser multiplataforma y no requerir software adicional para su funcionamiento; basta con que el usuario tenga internet con una capacidad de conexión doméstica, es decir, lo más accesible para la mayoría de sus potenciales usuarios. Se utilizaron metodologías instruccionales contemporáneas para lograr un entorno virtual de apren- dizaje de los aspectos teóricos, aplicados y actitudinales referentes al desarrollo lingüístico infantil y los problemas que se derivan de ellas en los niños de edad preescolar. En esta sección se describen los aspectos metodológicos y el proceso de creación para conformar el laboratorio.

\section{Aprendizaje basado en casos de ABP como diseño instruccional}

La metodología de diseño instruccional y de enseñanza de este laboratorio virtual es el aprendizaje basado en problemas (ABP); desde esta metodología el laboratorio se centra en usar problemas como punto de partida para adquirir e integrar nuevos conocimientos (Morales y Landa, 2004; Santillán, 2006; Matus y Guzmán, 2009).

Desde el ABP, el Laboratorio Virtual de Enseñanza promueve en los estudiantes identificar qué conocimientos tienen para resolver un problema simulado y cuáles son los que les hacen falta. De esta forma, al identificar las necesidades de aprendizaje los estudiantes buscan información que les permita resolver el problema, y por ende desarrollar habilidades metacognitivas e interpersonales (Carvalho, 2016). Algunas de dichas habilidades son de orden cognitivo, como el pensamiento crítico, la toma de decisiones, capacidad de búsqueda y análisis de información; otras se relacionan con la motivación y el desarrollo de habilidades de aprendizaje para la elaboración de un modelo propio de trabajo, lo que permite al estudiante integrar el conocimiento obtenido y hacerse responsable de su aprendizaje; por lo tanto, a través del ABP el Laboratorio Virtual de Enseñanza se fomentan habilidades perdurables, es decir, el estudiante guía su desarrollo y aprendizaje mediante las actividades que se le presentan y en un continuo puede demostrar la puesta en práctica de las habilidades mencionadas (Branda, 2004; Matus y Guzmán, 2009; Dirección de Investigación y Desarrollo Educativo, 2007).

Dentro de este laboratorio virtual, el diseño instruccional basado en el modelo del ABP permite promover las mismas habilidades de esta metodología mediante herramientas interactivas que se integraron en el Laboratorio para este fin, como los videos, imágenes, problemas simulados, en los que el estudiante tiene que responder con base a la información que se le presenta en las lecciones problematizantes e investigar acerca de cómo resolverlo, y en los game learning prueba diferentes soluciones que le permitirán valorar las consecuencias para que sus aprendizajes y habilidades desarrolladas sean significativas, es decir, para que pueda aplicar el aprendizaje en un contexto real, donde tendrá que atender casos reales con los niños, respecto al desarrollo del lenguaje y los problemas de comunicación o del habla que presenten; después de 
haber experimentado en un contexto en línea que, como dice Agdas (2013), motiva a los estudiantes.

\section{Procedimiento de creación del Laboratorio Virtual de Enseñanza con ABP}

Se logró concretar la metodología del ABP en un proceso instruccional que implicó seis fases; las primeras cuatro se dieron en tiempos secuenciales y las últimas dos de manera simultánea. El análisis fue la primera fase; se revisaron de manera extensiva las diferentes necesidades: el propósito del simulador, los conocimientos y habilidades que se deseaba adquieran los estudiantes en el laboratorio, lo que se hizo a partir de una matriz de resultados de aprendizaje que permitió desglosar por dimensiones los aprendizajes a nivel cognitivo, procedimental y actitudinal (Ma Watson et al., 2016; Simmons, 2013). Los resultados de aprendizaje permitieron delimitar los contenidos viables y medios. También se establecieron las características de los participantes que usarían el laboratorio virtual, los recursos tecnológicos y el ambiente de trabajo que se deseaba en la interfaz.

La segunda fase fue el diseño; se siguieron las especificaciones del análisis y se esquematizó el diseño instruccional basado en el modelo del ABP del sistema basado en casos y problemas simulados del lenguaje infantil y sus problemas más comunes; a partir de ellos se enseñan competencias profesionales para evaluar y atender el desarrollo lingüístico o detectar problemas del habla, tomar decisiones acerca de las mejores alternativas de atención; se definió un sistema de evaluación que consistió en retroalimentaciones y seguimiento de trayectoria del estudiante para que puedan recibir de manera automática dirección y comentarios de las decisiones que están tomando los estudiantes ante los problemas que se les expone en el laboratorio; también se atendió la estructura de navegación y diseño de la interfaz gráfica: banner, botones, pestañas, títulos, imágenes.

En la tercera fase se efectuó el desarrollo del laboratorio virtual, se configuró el laboratorio integrando los elementos instruccionales basados en el modelo del ABP y del diseño de la interfaz. En la cuarta fase de evaluación se comenzó con determinar cuáles fueron las fallas a nivel de análisis, diseño y desarrollo; esto se hizo con los colaboradores del proyecto, y después se puso a prueba con un grupo de primeros usuarios que conformaron el grupo piloto de estudiantes, de los cuales se presentan los resultados en este artículo.

\section{Composición del Laboratorio Virtual de Enseñanza}

El Laboratorio Virtual de Enseñanza consta de módulos, que están enfocados a enseñar principios básicos teóricos y procesos aplicados del desarrollo de habilida- des lingüísticas de niños en preescolar y sus problemas más comunes, mediante los diversos recursos que posee, como preguntas problema, ejercicios de autoevaluación, videos, lecciones de simulación, exámenes y juegos con base en los principios que establece el ABP; siendo la herramienta para su aprendizaje, el Laboratorio Virtual de Enseñanza permite desarrollar competencias y habilidades, tanto cognitivas como interpersonales, de modo que al estudiante le permite ampliar su repertorio al afrontar problemáticas; en este caso específico, las que se relacionan al desarrollo de habilidades lingüísticas en niños en preescolar, los problemas más comunes a esa edad como las dislalias, y así tomar una mejor y eficaz decisión en el campo real aplicado. Los módulos con que cuenta el Laboratorio Virtual de Enseñanza se aprecian en la tabla 1.

\section{Tabla 1.}

Módulos componentes del Laboratorio virtual de enseñanza por $A B P$

\begin{tabular}{|c|c|c|}
\hline TEÓRICOS & ApLICAdos & ACTITUDINALES \\
\hline $\begin{array}{l}\text { - Enfoque } \\
\text { psicolingüístico } \\
\text { del desarrollo del } \\
\text { lenguaje } \\
\text { - Alfabetización } \\
\text { emergente como } \\
\text { referente para } \\
\text { desarrollar el } \\
\text { lenguaje oral y }\end{array}$ & $\begin{array}{l}\text { - Promoción de } \\
\text { las habilidades } \\
\text { lingüísticas en el } \\
\text { aula. } \\
\text { - Evaluación del } \\
\text { lenguaje infantil. } \\
\text { - Atención a las } \\
\text { dislalias }\end{array}$ & $\begin{array}{l}\text { - Ética y } \\
\text { responsabilidad } \\
\text { social. }\end{array}$ \\
\hline
\end{tabular}
escrito.

Cada uno de los módulos contiene lecciones problematizantes, problemas constituidos por elementos reflexivos diseñados con los principios del ABP, los cuales requieren un aprendizaje previo de habilidades o aspectos teóricos para así ser resueltos, y exámenes finales de cada una de las lecciones problematizantes, para que el estudiante compruebe que ha adquirido el conocimiento, destrezas y habilidades que ofrecen los módulos.

El módulo de enfoque psicolingüístico del desarroIlo del lenguaje está diseñado para que los estudiantes reconozcan cómo se da la adquisición del lenguaje y su importancia, describir y reconocer las etapas del desarrollo lingüístico, diferenciar los componentes del lenguaje y qué factores extrínsecos e intrínsecos pueden incidir en el desarrollo del lenguaje. También conocerá las bases, definiciones, etapas y objetivos básicos de la psicolingüística, las diversas teorías psicolingüísticas referentes al desarrollo del lenguaje, y conocer en qué consiste la comprensión y producción lingüística. Al finalizar el módulo el estudiante logrará identificar, desde 
un enfoque psicolingüístico, el curso normal del desarrollo del lenguaje en niños en edad preescolar.

El módulo de alfabetización emergente como referente para desarrollar los lenguajes oral y escrito está enfocado a que los estudiantes identifiquen la importancia y características de la alfabetización emergente, relación con las habilidades lectoras, analizar evidencia empírica que relaciona las habilidades de alfabetización emergente con el ambiente escolar y en el hogar, y apreciar los tipos de intervención en alfabetización emergente. Al término de este módulo el estudiante podrá comprender el estado del arte de la investigación acerca de habilidades de alfabetización emergente en niños en edad preescolar, para apreciar los hallazgos que hay al respecto y la propuesta a futuro desde la visión de Whitehurst y Lonigan (1998).

En cuanto al módulo aplicado de promoción de las habilidades lingüísticas en el aula, se pretende que el estudiante logre distinguir los componentes de la conciencia fonológica, reconocer las características de la conciencia silábica, fonémica, vocabulario receptivo y escritura emergente en niños en etapa preescolar, las cuales podrán practicar mediante problemas o casos presentados en videos, sobre qué estrategia didáctica para impulsar el desarrollo del lenguaje en niños preescolares utilizaría, siendo evaluados mediante actividades como preguntas de falso y verdadero, relación de columnas y opción múltiple. Al finalizar este módulo el estudiante logrará distinguir las características de los componentes de la alfabetización emergente, así como elegir y aplicar las estrategias adecuadas para impulsar el desarrollo del lenguaje en preescolares.

Un ejemplo de cómo se presentan los problemas de ABP en el Laboratorio Virtual de Enseñanza, se muestra en la tabla 2.

Tabla 2.

Ejemplo de problema ABP que resuelven los estudiantes.

\section{Problemas ABP}

“Luisita tiene 4 años, pero maneja pocas palabras, lo que le impide explicar sus ideas o darse a entender. Eso ha ocasionado que utilice muchos gestos $y$ ruidos para reemplazar palabras" Lo que se le pide al alumno, es identificar qué habilidad lingüística le hace falta desarrollar y que sugiera estrategias.

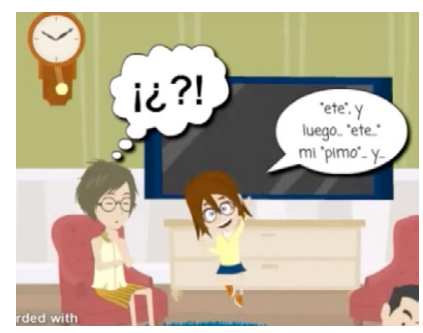

El módulo de atención a las dislalias tiene como objetivo que el estudiante sea capaz de distinguir las características de la intervención en los casos de dislalias, seleccionar y emplear las distintas estrategias de intervención en dislalias, intervenir mediante las actividades propuestas para practicar las estrategias aplicables a los diferentes casos de dislalias, identificar el contexto del caso de dislalia e intervenir de acuerdo con lo que se requiera.

Para el módulo actitudinal de ética y responsabilidad social se contemplaron las temáticas éticas de la responsabilidad social universitaria, formando una actitud y disposición del profesionista; en este caso específico, que anteponga los derechos y las necesidades de la sociedad en que se realizan servicios como evaluación e intervención, antes que cualquier oportunidad de éxito propio. Además, se inculcan principios éticos que a nivel universidad se tienen y que, siendo parte de esta comunidad, debe seguir. En cuanto a la ética, trata acerca de cómo el estudiante se comporta y qué actitud tiene respecto a las funciones universitarias sociales y de su profesión. Tiene que ver también con el comportamiento, disposición y el respeto que se da a la población que atiende y que sea responsable con el servicio que ofrece. Al finalizar este módulo, el estudiante podrá apropiarse y poseer una actitud de responsabilidad social universitaria y relacionarse con los problemas sociales que atiende la universidad (Díaz-Barriga, Pérez-Rendón y Lara Gutiérrez, 2016). Asimismo, diferencia la ética de la moral, la importancia de la ética en psicología y en la UNAM, así como sus principales fundamentos e instrumentos que se relacionan con la ética.

También se cuenta con un módulo de evaluación que dispone herramientas de evaluación digitales para el desarrollo de las habilidades lingüísticas orales y escritas para niños en preescolar y la atención de las dislalias.

Algunos componentes que comparten todos los módulos son los game learning, diseñados para que el estudiante retroalimente el aprendizaje adquirido dentro del módulo; además representan una manera interactiva para aprender y poner a prueba su conocimiento. La presentación o el diseño de los game learning desarrollados con la metodología del ABP tiene un efecto en los estudiantes respecto a cómo participan en éstos, facilitando el aprendizaje y motivación (Deen, Van Den Beemt y Schouten, 2015). Los game learning están relacionados directamente con el contenido de las lecciones problematizantes, y así desarrollar las habilidades y competencias que permite el Laboratorio Virtual de Enseñanza.

Los módulos están diseñados de manera que el conocimiento es integral, lo que quiere decir que, para seguir avanzando y finalizar las lecciones problematizantes, el alumno debe ser capaz de discernir acerca de los conocimientos que posee o no respecto al módulo. Los problemas también están diseñados de modo que si el estudiante no los contesta correctamente no podrá acceder a un examen final de la lección, indicando que carece de las habilidades y destrezas necesarias, por lo que tendrá 
la opción de volver a manipular la lección problematizante e identificar qué conocimientos o habilidades no ha adquirido, Ilevándolo a la búsqueda de información necesaria en la biblioteca digital del laboratorio virtual o por su propia cuenta, siendo de esta forma responsable de su propio aprendizaje, como lo indica el ABP.

\section{Rango de aplicación de la innovación}

El Laboratorio Virtual de Enseñanza desde el ABP que en este artículo se expone, es un entorno que podrá atender en primera instancia a estudiantes de las modalidades e-learning y b-learning de psicología, pedagogía, normalistas y todas las profesiones afines al estudio y atención del desarrollo infantil que tengan que realizar programas para los problemas más comunes en la etapa inicial y preescolar, como las dislalias. Ya que los estudiantes de carreras en línea no cuentan con muchos entornos enriquecidos para su aprendizaje, esta propuesta es muy idónea para ellos. Aunque es posible buscar simulaciones o laboratorios en internet, como los que se vieron en la sección anterior, algunos de ellos sólo dan acceso a los estudiantes matriculados en la universidad a la que pertenece el laboratorio virtual; en contraste, este laboratorio virtual da acceso a estudiantes de la propia universidad donde fue creado, como a todo estudiante universitario de otras instituciones que pudiera interesarse, así como a los académicos que gusten implementarlo.

Aunque es un recurso virtual, no quiere decir que los estudiantes de carreras presenciales no puedan usarlo; al contrario, al ser un recurso en línea, todo interesado en el tema y que tenga la afinidad formativa necesaria vinculada con la psicología infantil podrá acceder al Laboratorio Virtual.

Una vez concebido el Laboratorio Virtual de Enseñanza, se desarrolló su diseño en una serie de procedimientos metodológicos con ABP; en diferentes etapas y en distintos momentos se creó cada uno de sus módulos; el último y más reciente fue "Atención a las dislalias".

\section{FunCIONAMIENTO DE LA INNOVACIÓN}

Una vez diseñado el Laboratorio Virtual de Enseñanza, se hizo una invitación para ofertarlo a un grupo piloto de manera gratuita; se ofreció a 203 profesionales de la educación preescolar, quienes hicieron uso del laboratorio durante dos meses antes de terminar el ciclo escolar; por lo tanto, la convocatoria de invitación y selección de los participantes al grupo piloto fue por muestreo no probabilístico, ya que era necesario fueran estudiantes con alguna experiencia de trabajo en el ámbito infantil o preescolar específicamente. Se les solicitó valorar el tipo de experiencias que se presentan en el Laboratorio Virtual y se recopiló la opinión de los participantes acerca del fun- cionamiento del Laboratorio Virtual. Respecto a los datos personales de los participantes (nombre completo, edad, dirección de correo electrónico y RFC) sólo tenían acceso a dicha información los administradores del sitio, con la cual se creó el perfil de cada participante para que pudieran acceder al sitio, además de que éste registraría los accesos a los diversos módulos y actividades que ofrece la plataforma; los datos son resguardados y no se utilizan para publicidad ni ningún otro uso no autorizado.

Primero se presentan las características generales de los participantes para comprender mejor sus opiniones.

\section{Características de los participantes}

Los estudiantes que accedieron al Laboratorio Virtual de Enseñanza por ABP fueron 203, de los cuales 7\% fueron hombres y $97 \%$ mujeres, con alguna experiencia o relación con el ámbito de educación preescolar y pertenecientes a la zona metropolitana de la Ciudad de México. La edad promedio de los participantes fue de 39 años, y el rango fue amplio con personas de 22 a los 60 años.

La figura 1 muestra que los participantes de 22 a 40 años de edad está el $57 \%$ de los que integraron el grupo. En si el rango de edad menos presente pero con una porción importante fueron los participantes de más de 50 años.

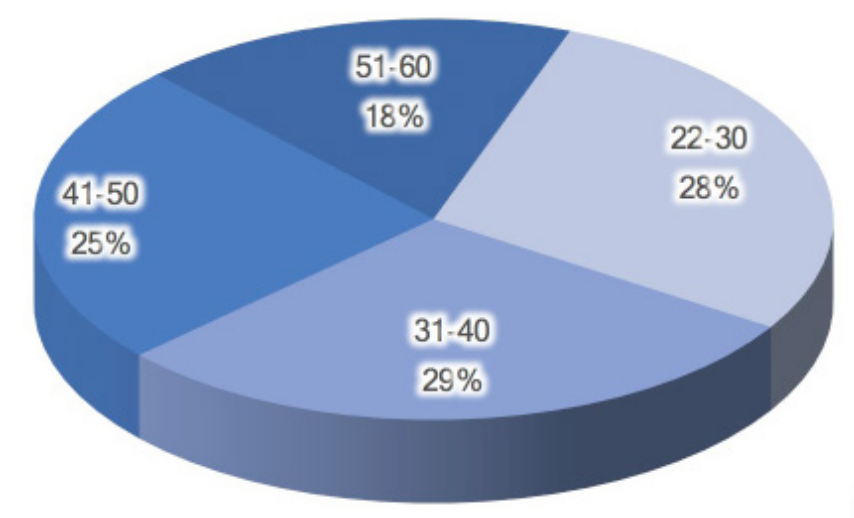

Figura 1.

Edad de los participantes por rangos de 10 años

Con esto se puede ver que hubo participantes pertenecientes a diferentes generaciones que han vivido los cambios tecnológicos de formas distintas por sus habilidades, familiaridad con la tecnología y cierta predisposición a su uso, es relevante mencionarlo porque, independientemente de la edad, esta fue la primera vez que todos los participantes utilizaban un entorno virtual; ni si quiera habían tenido alguna experiencia con cursos en línea.

\section{Resultados del funcionamiento del Laboratorio virtual}


El funcionamiento del Laboratorio Virtual de Enseñanza por ABP se estimó con dos fuentes; una fue el registro de actividad obtenido por los longs de los usuarios que recaba la plataforma con que se diseñó el Laboratorio Virtual, y la segunda fue la opinión de los participantes con una encuesta en línea montada en el Laboratorio Virtual, que contestaban una vez terminadas las actividades de los diferentes módulos; ésta contempló tres categorías: 1) utilidad del Laboratorio virtual; 2) aspectos didácticos del aprendizaje basado en problemas, y 3) navegación e interfaz del Laboratorio Virtual.

\section{Registro de actividad}

Respecto al registro de la actividad en el Laboratorio Virtual, se obtuvo un mapeo gráfico de tres módulos de dicho laboratorio, que se pusieron a prueba primero. Como se muestra en la figura 3, el módulo teórico ("Enfoque psicolingüístico del desarrollo del lenguaje") y sus actividades fue el primero al que tuvieron acceso los participantes, y fue el que mayor actividad registró, con una frecuencia que osciló entre 500 y 11,000 registros por día; esto puede deberse a la novedad de los recursos, además que exigió mayor desempeño de los participantes porque ninguno tenía experiencia previa con entornos virtuales similares ni cursos en línea, y al comenzar a trabajar con los módulos siguientes los registros de actividad fueron menores, con un promedio de 2,500 registros. La figura 2 muestra una alta participación por parte del grupo.

Ahora bien, en los accesos que se registraron para las lecciones problematizantes, se puede apreciar en la figura 3 que en el caso de las lecciones del módulo "Enfoque psicolingüístico del desarrollo del lenguaje", son muy parecidas entre sí, siendo la máxima 2,947 registros, y de más de 3,000 registros en la lección "Alfabetización emergente como referente para desarrollar los lenguajes oral y escrito". Se aprecia que los participantes tuvieron mucha actividad en los módulos que menos se esperaba la tuvieran; el registro mayor se suponía se tendría en lecciones problematizantes para la promoción en el aula.

Un componente de las lecciones problematizantes por ABP son actividades donde los participantes toman decisiones para resolver problemas, y éstos son autoevaluativos. En la figura 4 se aprecia cómo interactuaron los participantes en ellos; les demandó alta actividad interactiva la mitad del tiempo que estuvieron disponibles, y al final los registros descendieron debido al dominio que alcanzaron los estudiantes. Respecto a las actividades autoevaluativas, éstas se construyeron como indican Constantino y Llull (2010), acordes y coherentes con el modelo instruccional, en este caso ABP, los objetivos y las competencias que se buscan promover, así como las actividades se utilizaron para lograr esto.

En otras de las actividades que brinda el Laboratorio Virtual de Enseñanza por ABP, los game learning, diseñados para el aprendizaje de los procesos outside-in, inside-in y dominios de la alfabetización emergente, se aprecia en la figura 5 que el registro de actividad fue mucho más bajo que las lecciones problematizantes. EI game learning con mayor número de accesos fue el de aprendizaje de la alfabetización emergente.

Ahora bien, que los game learning se hayan desarrollado con base a los principios que establece el ABP, tiene un impacto positivo en cómo es que los estudiantes participan en ellos, facilitando, en este caso, el aprendizaje sobre el desarrollo del lenguaje. Así mismo, resulta de suma importancia que el contenido de las lecciones problematizantes propician que los objetivos, destrezas y habilidades establecidas por los módulos del Laboratorio Virtual de Enseñanza, se logren cumplir más fácilmente (Deen, Van Den Beemt y Schouten, 2015; Garris, Ahlers y Driskell, 2002).

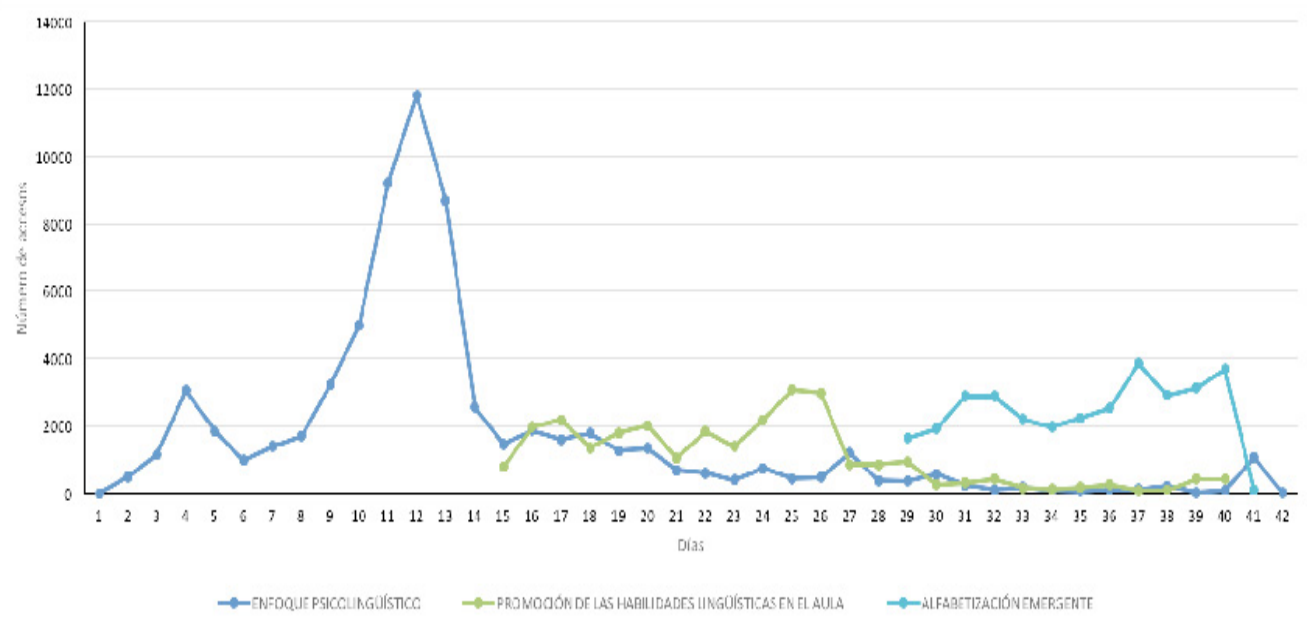

Figura 2.

Registros de actividad en tres módulos del Laboratorio Virtual 


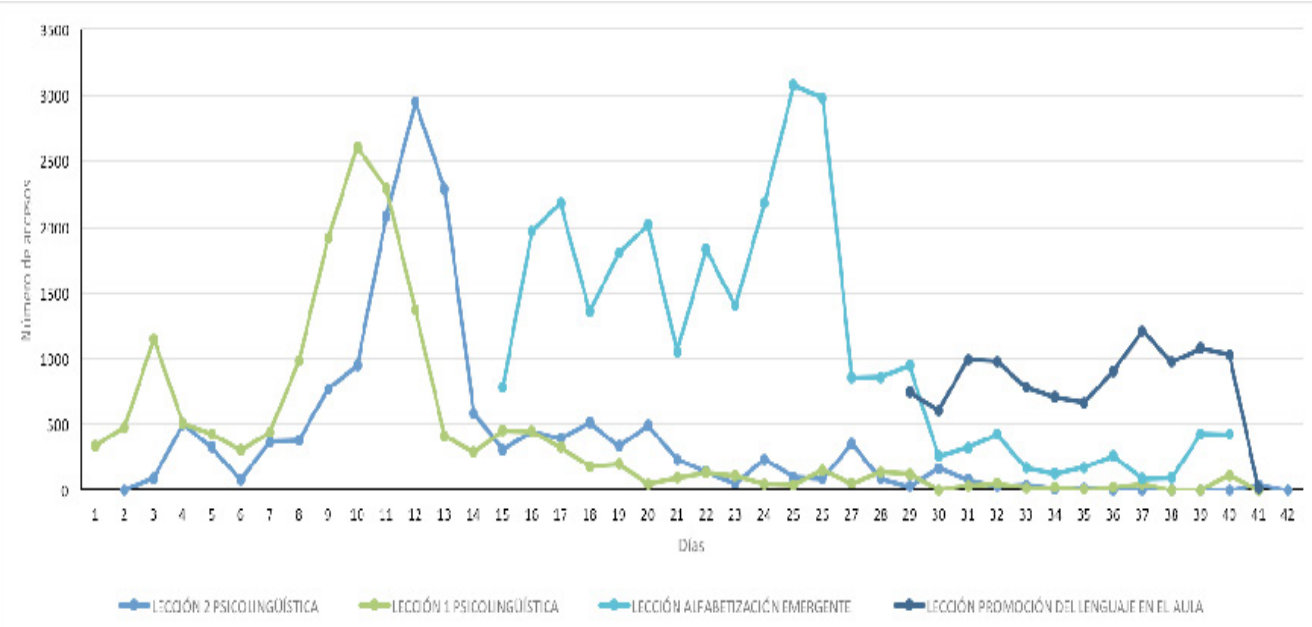

Figura 3.

Registro de actividad en las lecciones profesionalizantes

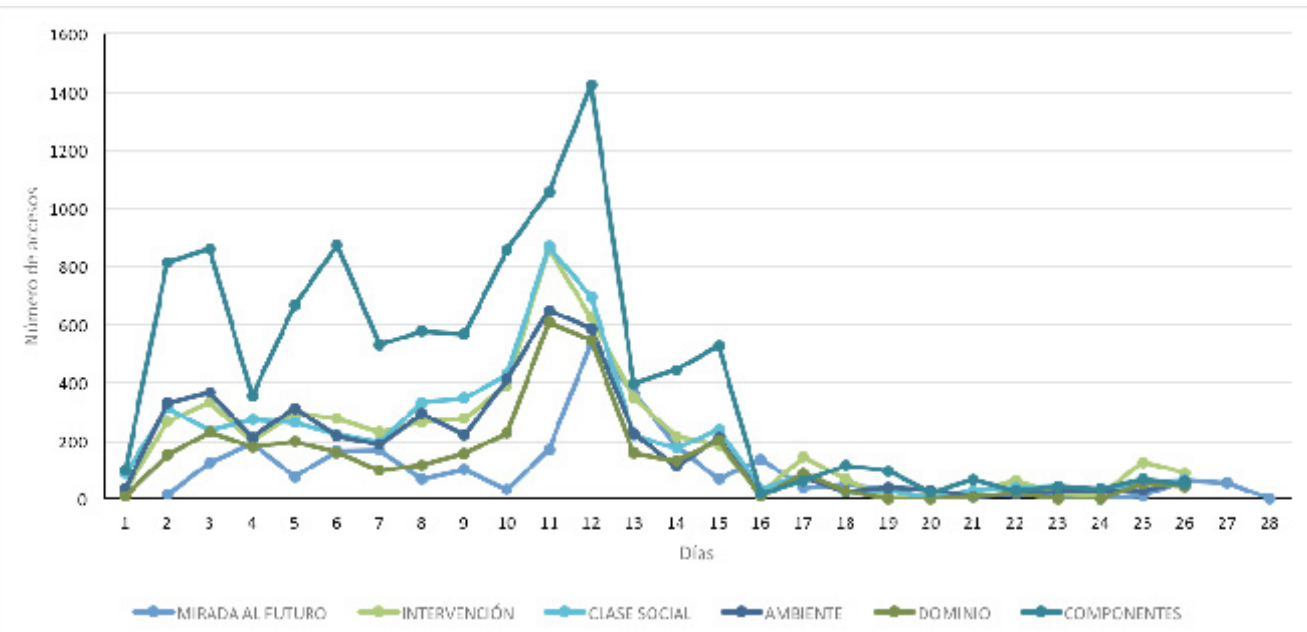

Figura 4.

Registro de las actividades auto-evaluativas.

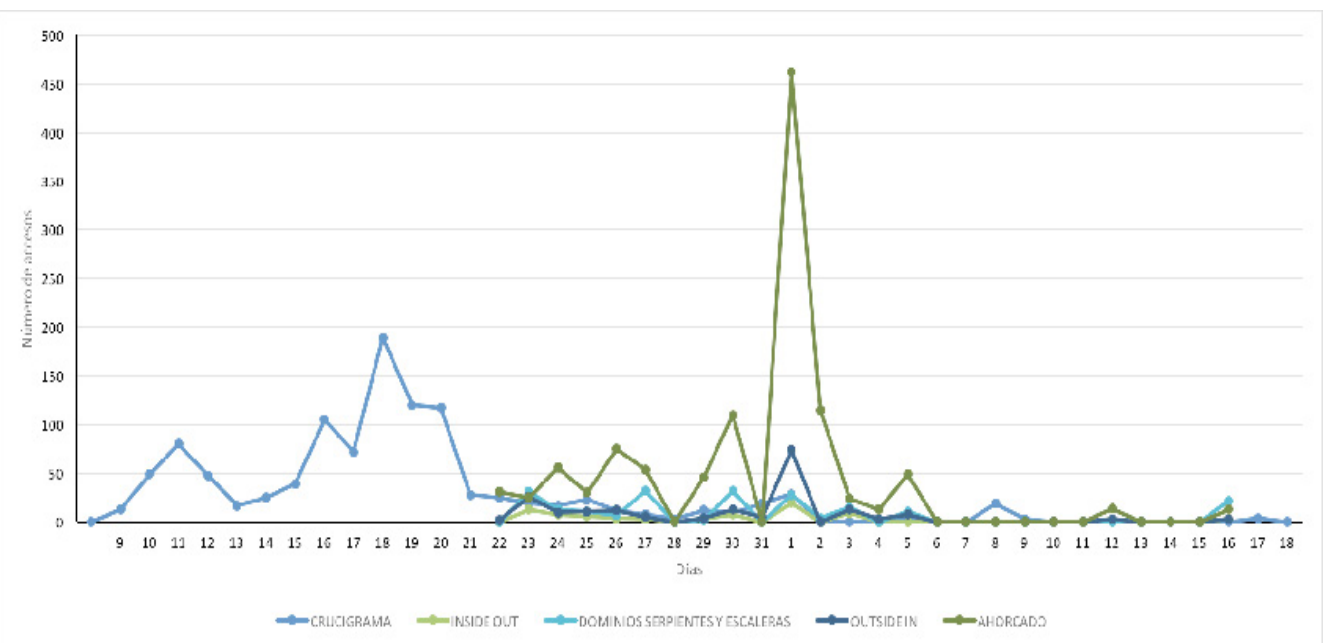

Figura 5.

Registros de actividad en los game learning. 
El tipo de evaluación que se utiliza en el Laboratorio Virtual de Enseñanza por ABP con los game learning y las actividades autoevaluativas atiende las particularidades de los nuevos escenarios, teorías, paradigmas y modelos que se vinculan con el desarrollo tecnológico, siendo capaz de afrontar los cambios y previendo los avances que reconfigurarán la educación a distancia, permitiendo de esta manera generar nuevos conocimientos y aprendizajes (Constantino y Llull, 2010).

Por otra parte, la sección donde se encuentra la biblioteca digital, como puede observarse en la figura 6 , el módulo en el cual hubo mayor número de visitas $(1,164)$ fue el "Enfoque psicolingüístico del desarrollo del lenguaje", seguido por "Promoción de las habilidades lingüísticas en el aula", con 589, y por último el de "Alfabetización emergente como referente para desarroIlar los lenguajes oral y escrito", con 492 accesos; aunque la frecuencia de uso de la biblioteca fue menor a otros componentes del Laboratorio Virtual, es esperado este resultado porque la mayor demanda de interactividad para los estudiantes está en las lecciones problematizantes y las actividades autoevaluativas. Sin embargo, esto muestra que sí exploraron e investigaron acerca de los aprendizajes que se programaron.

La función que tiene la biblioteca digital y sus materiales de información es complementar el aprendizaje, para hacerlos útiles y relevantes (Bryndum y Jerónimo, 2013). Se tiene en cuenta también que la presencia y uso de estos recursos en ambientes virtuales resultan fundamentales para el alumno, pues puede desarrollar más fácilmente las habilidades y destrezas que se le demandan.

\section{Evaluación del usuario acerca del Laboratorio virtual}

Esta evaluación se hizo mediante una encuesta de opinión que ofreció otra visión del Laboratorio Virtual desde la óptica de los estudiantes que han tenido experiencia con el ámbito infantil,

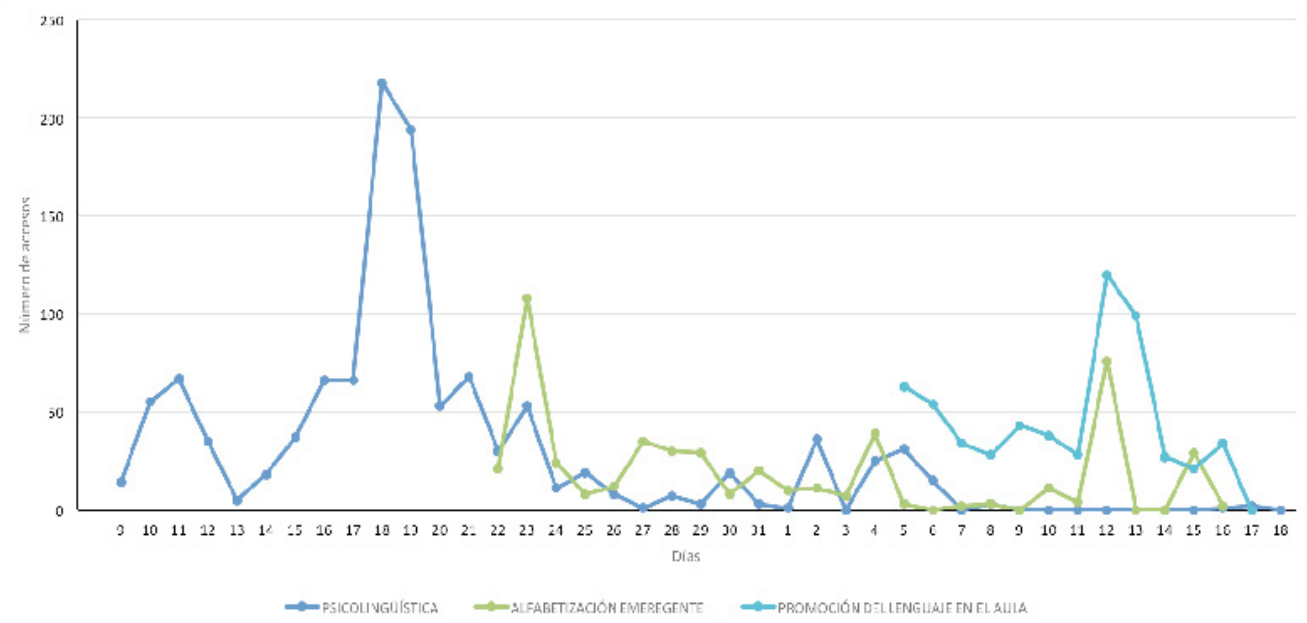

Figura 6.

Registros de visitas a la biblioteca digital del Laboratorio virtual.

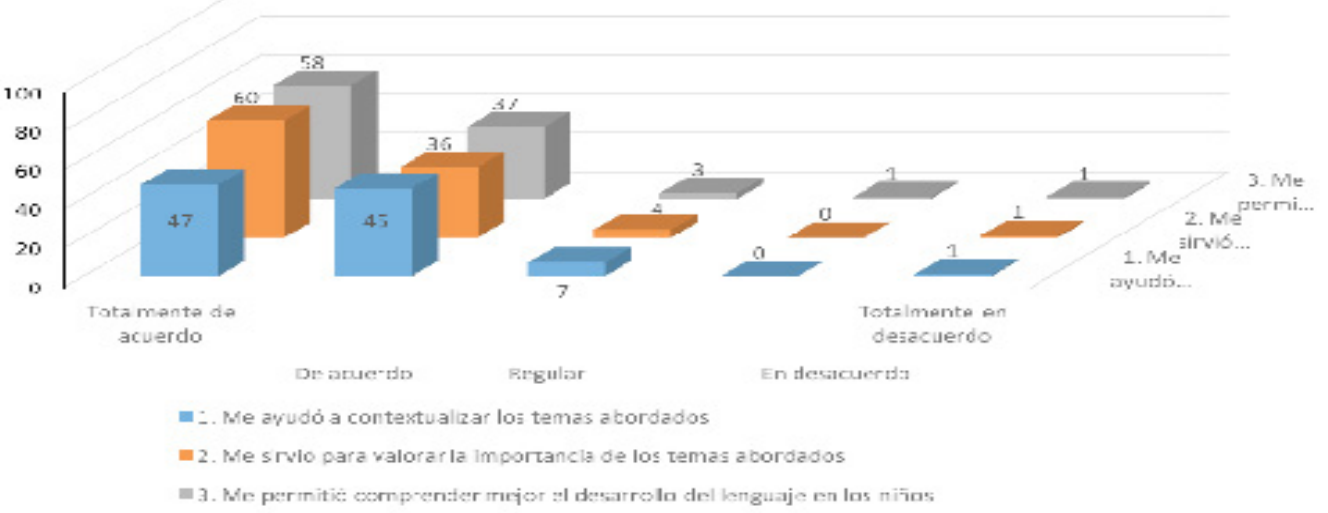

Figura 7.

Utilidad del Laboratorio virtual por ABP en porcentaje. 
pero nunca con un entorno virtual. En el primer aspecto manifestaron que el Laboratorio Virtual fue de utilidad.

En la figura 7 se indica que el mayor porcentaje de participantes considera estar totalmente de acuerdo con que el Laboratorio Virtual les es útil, ayudándoles a contextualizar y valorar la importancia de los temas abordados, y comprender mejor el desarrollo del lenguaje en los niños.

Respecto a la didáctica empleada en el Laboratorio Virtual, es decir el ABP, en su mayoría los participantes consideran que las lecciones problematizadoras, las actividades autoeveluativas desde el ABP, les permitieron aprender (figura 8).

Finalmente en la figura 9 se ve que la mayoría de los participantes están de acuerdo o totalmente de acuerdo en que el laboratorio virtual de enseñanza por ABP cuenta con una navegación clara, con secciones diferenciadas y con imágenes que aportan a la comprensión del contenido, también consideran que el Laboratorio virtual tiene un diseño agradable y estructura amigable.

\section{Discusión}

Como se aprecia en los resultados de este trabajo, el Laboratorio Virtual de Enseñanza desde el ABP propició en los estudiantes muchos registros de actividad en las lecciones problematizantes y en las actividades autoevaluativas; esto es entendible ya que son los dos componentes donde se propicia toda la interactividad del diseño instruccional del aprendizaje basado en problemas, que demanda del estudiante varias acciones; primero, habilidades metacognitivas porque debe identificar los conocimientos que tiene para resolver un problema simulado y cuáles son los que le hacen falta; después debe buscar información que le permita resolver el problema (puede buscar en la biblioteca digital del Laboratorio o en otras fuentes); luego regresa a la lección problematizante para poner a prueba una solución; en el momento en que las habilidades cognitivas del estudiante se muestran en la formulación de soluciones, pone en práctica el pensamiento crítico, analiza información y toma decisiones.

Las retroalimentaciones inmediatas de las lecciones propiciaron la motivación y mantenerse conectado para concluir los casos presentados en las lecciones, en si fue capaz de desarrollar habilidades de aprendizaje para la elaboración de un modelo propio de trabajo, lo que permite al estudiante integrar el conocimiento obtenido y hacerse responsable de su aprendizaje, que es uno de los objetivos del ABP (Van Oostveen, Childs, Flynn y Clarkson, 2014); esto se sabe porque el sistema de evaluación del Laboratorio Virtual corresponde con los resultados de aprendizaje con que fueron diseñadas las lecciones, game-learning y actividades autoevaluativas. De acuerco con Ausín, Abella, Delgado y Hortigüela (2016), se puede afirmar que el Laboratorio Virtual de Enseñanza por ABP es una metodología conveniente porque al compararlo con entornos de enseñanza tradicional se ha demostrado que los estudiantes de entornos ABP muestran una mejor capacidad para la resolución de problemas y más comprometidos, autosuficientes y con mayor capacidad atencional, lo cual es favorecedor sobre todo en los sistema de educación en línea, donde se requiere autorregulación por parte de los estudiantes porque no tienen los controles que ofrece un salón de clase o un laboratorio físico donde un profesor — en un horario establecido- dirige las actividades que realizan.

Según la opinión de los participantes, el Laboratorio Virtual de Enseñanza es un recurso práctico para adquirir conocimientos y habilidades que les permitieron implementarlos en su labor diaria con los niños; además, por su interfaz amigable y navegación accesible, es un entorno muy adecuado para estudiantes con o sin experiencia en entornos virtuales —o de otro tipo- a distancia.

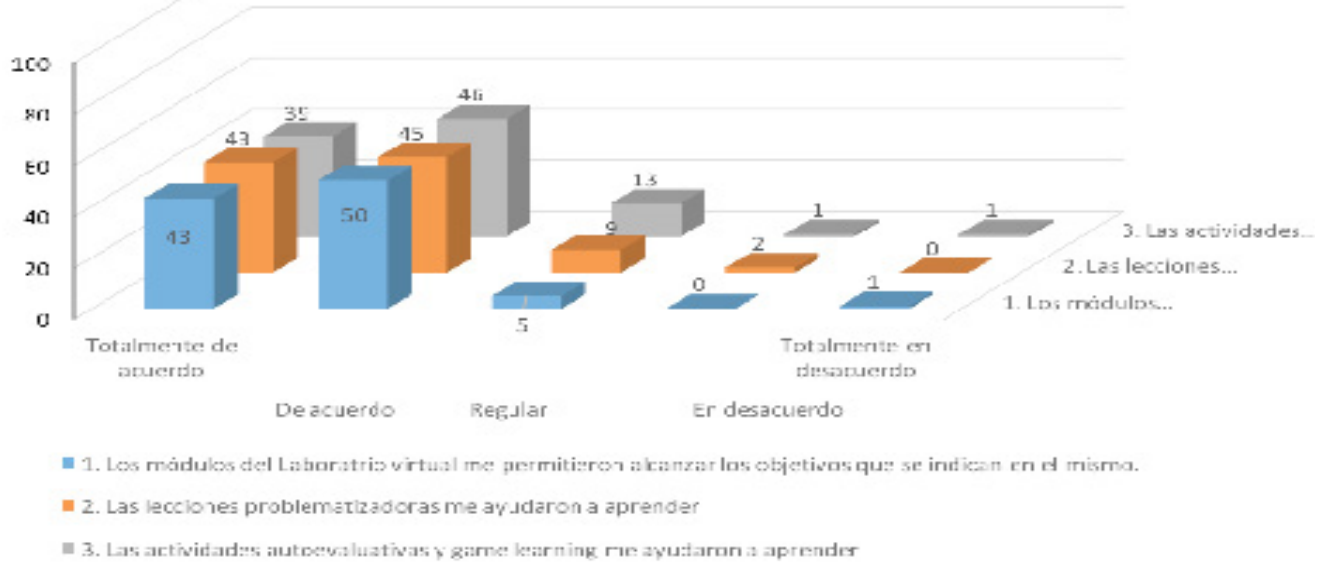

Figura 8.

Didáctica del ABP del Laboratorio virtual 


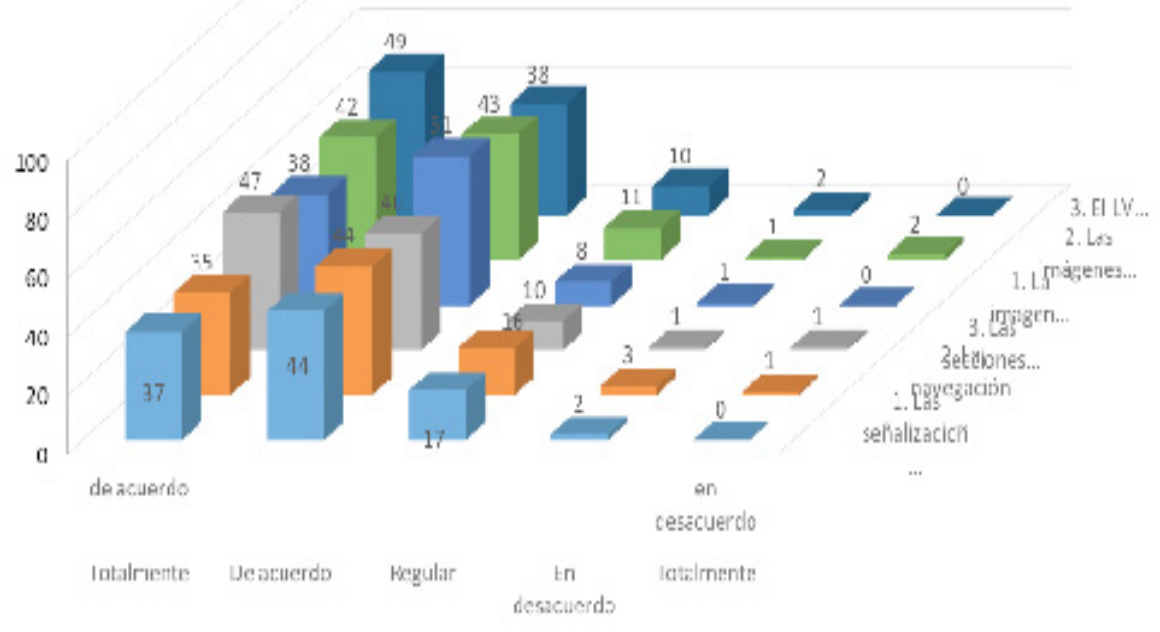

Figura 9.

Navegación e interfaz del Laboratorio virtual por $A B P$

A pesar de su bondad, el ABP en los ambientes en línea o virtuales aún no es muy extendido; como encontraron Jin y Bridges (2014) en una revisión sistemática de estudios acerca del uso y los efectos de las tecnologías educativas con el ABP en ciencias de la educación para la salud, sólo tres de 28 artículos exponen hallazgos del ABP en ambientes virtuales de aprendizaje; esto muestra que aun en el área de la salud, que es donde surge esta metodología, en los entornos o ambientes de aprendizaje en línea no se ha extendido, quizá por el conocimiento especializado que implica su diseño y programación, como lo fue en el caso del Laboratorio Virtual presentado.

Asimismo, queda pensar si el ABP ha sido una metodología adecuada en las ciencias de la salud, donde la aplicación exacta de los conocimientos científicos de la medicina deben ser aplicados para el cuidado de la salud con una alta responsabilidad ética y profesional, porque en la psicología no ha sido explorada; si también se tiene a cargo el bienestar de las personas y se busca su óptimo desarrollo en el caso de los infantes, sobre todo porque se han dejado de lado los laboratorios y no se han implementado innovaciones en ese sentido, si es en el laboratorio donde se podrían experimentar y practicar conocimientos aplicados y habilidades que el profesional de la psicología podría perfeccionar. Los laboratorios virtuales de psicología deberían ser una opción al alcance de estudiantes de sistemas a distancia, pero también presenciales, para posibilitar al estudiante de experiencias simuladas controladas que lo dispon- drían para ofrecer un mejor servicio en el campo de su práctica profesional. Estos planteamientos fueron los que llevaron a los autores de este trabajo a proponer y diseñar el Laboratorio Virtual de Enseñanza con ABP.

El Laboratorio Virtual de Enseñanza con ABP puede ofrecer, como han planteado Jin y Bridges (2014), resultados positivos para el aprendizaje del estudiante, proporcionar problemas auténticos ricos y/o contextos de casos para el aprendizaje; apoyar el desarrollo del estudiante de los conocimientos de su área mediante el acceso y estructuración de los conocimientos y habilidades del experto que diseña el entorno virtual; la toma de decisiones y estrategias explícitas de la disciplina, proporcionando en los laboratorios virtuales una plataforma para generar la articulación y la reflexión, así como la reducción de la carga cognitiva percibida.

\section{ConcLusiones}

Hoy en día se vive la era digital, que se caracteriza por la constante innovación tecnológica cambiando a la sociedad, sobre todo en el ámbito de las comunicaciones, como el internet; sin embargo, el campo educativo y de enseñanza no se ha quedado atrás. Las propuestas virtuales en México son escasas; por tanto, este artículo presentó el diseño y elaboración de un Laboratorio Virtual de Enseñanza, el cual desarrolla su contenido con base en el diseño instruccional basado en el modelo del ABP, 
que permite a los estudiantes simular procesos reales aplicados, para posteriormente enfrentar distintos tipos de problemas con un mayor repertorio de técnicas tanto teóricas como metodológicas, así como generar nuevos contextos de enseñanza-aprendizaje, tal como lo mencionan Faúndez, Bravo, Melo y Astudillo (2014).

La creación de un laboratorio virtual utilizando medios y herramientas tecnológicas digitales y ABP, no resulta fácil; sin embargo, en la UNAM el equipo del Laboratorio Digital de Desarrollo Infantil logró hacer la alternativa.

Respecto a las bondades que ofrece, es un espacio en línea que se adecua a las necesidades de los estudiantes que acceden a él; logran realizar una práctica o la simulación de problemas, libres de las restricciones tiempo-espacio de la enseñanza presencial, siendo este punto una gran ventaja ya que, mientras el estudiante tenga acceso a una computadora o dispositivo que se conecte a internet, puede navegar dentro del Laboratorio.

Este trabajo también cumple con las características que mencionan Meneces y Ordosgoitia (2009) y algunas otras que enlistan Marín, Rupérez, Userno y Arroyo (apud Bengochea e Hilera, 2012) respecto a los laboratorios virtuales: interfaz de usuario intuitiva y fácil de usar. Instrumentación simulada interactiva que posea una función similar a la de los instrumentos reales. Relaciona los conceptos teóricos con los prácticos mediante actividades y prácticas. Las acciones que toman los alumnos ocurren en tiempo real.

Gracias a la naturaleza del Laboratorio Virtual de Enseñanza, también cumple con los puntos que mencionan Griol, Sanchis, Molina y Callejas (2014) acerca de los procedimientos que principalmente pueden desarrollarse, gracias a los espacios de enseñanza virtual: acelerar el proceso de aprendizaje. Facilita el acceso al aprendizaje; permite personalizar el aprendizaje, logrando que sea más completo y significativo para el alumno.

Respecto a las innovaciones que están a la orden del día, la psicología no ha aprovechado del todo estas herramientas, quedando rezagado en comparación con el desarrollo que manifiestan disciplinas como la física o la química. La psicología debe aprovechar este desarrollo tecnológico para innovar el aprendizaje fuera del aula, como las herramientas que se utilizaron para el laboratorio virtual aquí presentado, y rebasar las limitaciones que presenta la práctica presencial: realizar prácticas en menor tiempo, simulaciones difíciles de efectuar en el campo real aplicado y, al no haber un profesor, el resultado es que el estudiante se torna responsable en cuanto a su aprendizaje, creando sus propios métodos (Benson, 2012; Griffiths, 2013; Rodríguez-Rivero, Molina-Padrón, Martínez-Rodríguez y Molina-Rodríguez, 2014; Infante, 2014). Se refuerzan estos últimos puntos debido al tipo de metodología empleada, el ABP, la cual repercute en el rendimiento, aprendizaje y disposición del pensamiento crítico del estudiante (Wayne, Lin, Ho y Wang, 2015).

Un punto importante que debe tenerse en cuenta, y con el que se coincide, es el mencionado por Faúndez, Bravo, Melo y Astudillo (2014), Rivera, Agudelo, Ramos y Vargas (2015) y Hack, McKillop, Sweetman y McCormack (2015) respecto a los cambios de roles que se presentan debido la manera de la enseñanza y cómo los estudiantes se tornan activos en su aprendizaje gracias a los laboratorios virtuales, pues tanto profesores como estudiantes deben aprender el manejo de herramientas multimedia y aplicaciones de software con las cuales realizar simulaciones de problemas relacionados con la vida cotidiana. Esto puede contribuir, además del desarrollo en la manera de enseñanza-aprendizaje fuera del aula, a que se contemplen en los currículos de las escuelas de cualquier nivel el uso de dichas herramientas multimedia, ya que facilitan el proceso de aprendizaje de los estudiantes (Benson, 2012; Griffiths, 2013; Rodríguez-Rivero, Molina-Padrón, Martínez-Rodríguez y Molina-Rodríguez, 2014).

Se puede concluir que el uso de los laboratorios virtuales permite que habilidades y aprendizajes que se desarrollan en un aula presencial sean más fácil demostrables en un entorno donde los estudiantes practican; incluso promueven aquellas que son difíciles de aprender porque es poco fácil experimentarlas en la vida real; también se puede programar aquellas que son peligrosas de llevar a cabo en la realidad siguiendo un modelo instruccional que fomente la resolución de problemas como el ABP (Yeo y Chee Tan, 2014).

En el caso del Laboratorio Virtual de Enseñanza, su desarrollo implica una manera de enseñanza y aprendizaje que se espera no sólo estudiantes de psicología utilicen, sino también los profesionales afines. Asimismo se pretende que esta innovación siga creciendo y contemplando más módulos de simulación.

\section{Referencias}

Agdas, S. (2013). Effects of Problem Based Learning on Development of Critical Thinking Skills and Dispositions in Engineering. ProQuest LLC, University of Florida.

Ausín, V., Abella, V., Delgado, V., y Hortigüela, D. (2016). Aprendizaje basado en Proyectos a través de las TIC: Una Experiencia de Innovación Docente desde las Aulas Universitarias. Formación Universitaria, 9(3), 31-38. https://dx.doi.org/10.4067/S0718-50062016000300005

Bengochea, L., e Hilera, J. (2012). Calidad y accesibilidad de la formación virtual. Universidad de Alcalá, Servicio de Publicaciones, España, pp. 200-205. Recuperado el día 9 de Julio de 2016 de http://www.esvial.org/wp-content/ files/LibroActasCAFVIR2012.pdf

Benson, S. (2012). The Relative Merits of PBL (Problem-Based Learning) in University Education. US-China Education 
Review A 4, 424-430. Recuperado el día 19 de junio de 2016 de http://files.eric.ed.gov/fulltext/ED533570.pdf

Branda, L. A. (2004). El aprendizaje basado en problemas en la formación en Ciencias de la Salud. En: El aprendizaje basado en problemas: Una herramienta para toda la vida, Madrid. Reuperado el día 3 de junio de 2016 de http:// campus.usal.es/ ofeees/NUEVAS METODOLOGIAS/ABP/ abpcienciassalud\%5B1\%5D.pdf

Bryndum, S., y Jerónimo, J. A. (2013). La motivación en los entornos telemáticos. RED. Revista de Educación a Distancia, 5:(13), 1-24. Recuperado el día 25 de junio de 2016 de http://www.um.es/ead/red/13/bryndum.pdf

Cardona, B. F. (2013). Las prácticas de laboratorio como estrategia didáctica. Universidad del Valle, Instituto de Educación y Pedagogía. Santiago de Cali, Colombia. Recuperado el día 17 de junio de 2016 de http://bibliotecadigital.univalle. edu.co/bitstream/10893/6772/1/CD-0395428.pdf

Carvalho, A. (2016). The Impact of PBL on Transferable Skills Development in Management Education. Innovations in Education and Teaching International, 53:(1), 35-47. Recuperado el día 19 de junio de 2016 de http://www. tandfonline.com/doi/full/10.1080/14703297.2015.1020327

Constantino, G., y Llull, L. (2010). Evaluación y calidad en los programas y cursos online en educación superior. Formación y docencia. Revista internacional de la educación científica, 8:(1), 225-233. Recuperado el día 26 de junio de 2016 de http://ojs.pensamultimedia.it/index. php/siref/article/view/1337/1302

Cornell University Center for Teaching (2017). Teaching Labs. Recuperado el 6 de julio de 2017 de http://www.cte. cornell.edu/teaching-ideas/labs-studios-discussions/ teaching-labs.html

Deen, M., Van Den Beemt, A., y Schouten, B. (2015). The Differences Between Problem-Based and Drill \& Practice Games on Motivations to Learn. International Journal of Gaming and Computer-Mediated Simulations, 7:(3), 4459. Recuperado el día 18 de junio de 2016 de, https:// www.researchgate.net/publication/281246873 The Differences between Problem-Based and Drill and Practice_Games_on_Motivations_to_Learn

Díaz-Barriga Arceo, F., Pérez-Rendón, M. M., y Lara Gutiérrez, Y. (2016). Para enseñar ética profesional no basta con una asignatura: los estudiantes de Psicología reportan incidentes críticos en aulas y escenarios reales. Revista iberoamericana de educación superior, 7(18), 42-58.

Dirección de Investigación y Desarrollo Educativo (2007). El Aprendizaje Basado en Problemas como técnica didáctica. Vicerrectoría Académica, Instituto Tecnológico y de Estudios Superiores de Monterrey. Disponible en http://sitios.itesm.mx/va/dide/documentos/inf-doc/abp. pdf

Faúndez, A. C., Bravo, A. A., Melo, D. A., y Astudillo, F. H. (2014). Laboratorio Virtual para la Unidad Tierra y Universo como Parte de la Formación Universitaria de Docentes de Ciencias. Formación Universitaria, 7(3). 33-40.

Flores, J., Sahelices, M. C. C., y Moreira, M. A. (2016). El laboratorio en la enseñanza de las ciencias: Una visión integral en este complejo ambiente de aprendizaje. Revistas de Investigación, 33(68).

Gamito, P., Oliveira, J., Baptista, A., Morais, D., Lopes, P., Rosa,
P., Santos, N. (2014). Elicit Nicotine Craving with Virtual Smoking Cues. CyberPsychology, Behavior and Social Networking. Vol. 17, No. 8: 556-561.

Garris, R., Ahlers, R., y Driskell, J. (2002). Games, Motivation, and Learning: A Research and Practice Model. Simulation and Gaming, 33(4), 441-467. DOI:10.1177/1046878102238607. Recuperado el día 18 de junio de 2016 de http://diegolevis. com.ar/secciones/Infoteca/vj_motivacion.pdf

Griffiths, W. (2013). The Effect of a Computer Virtual Lab Simulation on Learning in a High School Chemistry Class. ProQuest LLC, New York. Recuperado el 17 de junio de 2016 de http://gradworks.umi.com/35/81/3581625.html

Griol, D., Sanchis, A., Molina, J. M., y Callejas, Z. (2014). Utilización de las tecnologías del habla y de los mundos virtuales para el desarrollo de aplicaciones educativas. Procesamiento del Lenguaje Natural, 53(1), 167-170.

Hack, C., McKillop, A., Sweetman. S., y McCormack, J. (2015). An Evaluation of Resource Development and Dissemination Activities Designed to Promote Problem-Based Learning at the University of Ulster. Innovations in Education and Teaching International, 52:(2), 218-228. DOI: 10.1080/14703297.2013.849610. Recuperado el día 16 de junio de 2016 de http://dx.doi.org/10.1080/14703297.20 13.849610

Hoyos, K. C., López, G. C., Maldonado, J. G., Esquivel, F. R., \& Villalobos, G. T. (2015). Uso clínico de la realidad virtual para la distracción y reducción del dolor postoperatorio en pacientes adultos. Tesis Psicológica, 10(2), 38-50.

Infante, C. (2014). Propuesta pedagógica para el uso de laboratorios virtuales como actividad complementaria en las asignaturas teórico-prácticas. Revista Mexicana de Investigación Educativa, 19:(62), 917-937. Recuperado el día 19 de junio de 2016 de http://www.scielo.org.mx/scielo. php?script=sci arttext\&pid=S1405-66662014000300013

Jin, J., \& Bridges, S. M. (2014). Educational Technologies in Problem-Based Learning in Health Sciences Education: a Systematic Review. Journal of Medical Internet Research, 16(12), e251.

Laboratorio de Psicología Computacional. (Fecha de consulta: 19 de septiembre de 2015). Disponible en http://labpsicom. ulusofona.pt/

Lewis, J. (2015). A Comparison between two Different Activities for Teaching Learning Principles: Virtual Animal Labs Versus Human Demonstrations. Scholarship of Teaching and Learning in Psychology, 1:(2), 182-188. Recuperado de http://psycnet.apa.org/index.cfm?fa=buy. optionToBuy\&uid=2015-17274-001

Ma Watson, S. L., Loizzo, J., Watson, W. R., Mueller, C., Lim, J., \& Ertmer, P. A. (2016). Instructional Design, Facilitation, and Perceived Learning Outcomes: An Exploratory Case Study of a Human Trafficking MOOC for Attitudinal Change. Educational Technology Research and Development, 1-28. DOI: 10.1007/s11423-016-9457-2.

Matus, F. R., y Guzmán, P. J. (2009). Uso del Aprendizaje Basado en Problemas en un curso de matemáticas. Centro de Enseñanza Técnica y Superior, Tijuana. Recuperado el día 5 de junio de 2016 de http://www.fimpes.org.mx/ phocadownload/Premios/1Investigacion2009.pdf

Matute, H., Goikoetxea, E., Blanco, F., Moreno, M., Martínez, N., y Díaz, M. (2017). Labpsico. Laboratorio de Psicología 
Experimental de la Universidad de Deusto. Recuperado el día 6 de julio de 2017 de https://labpsicoblog.wordpress. $\mathrm{com} /$

Meneces, G. A., y Ordosgoitia, C. E. (2009). Laboratorio virtual basado en la metodología de Aprendizaje Basado en Problemas, ABP. Educación en Ingeniería, 7(1), 62-73.

Morales B. P., y Landa, F. V. (2004). Apendizaje Basado en Problemas. Problem-Based Learning. Theoria, Vol. 13, 145-127. Recuperado el día 5 de junio de 2016 de http:// campus.usal.es/ ofeees/NUEVAS_METODOLOGIAS/ ABP/13.pdf

Pomares, J., Candelas, F., García, G., Gil, P., Jara, C., Puente, S., Torres, F., Mira, D., y Pérez, J. (2014). Metodología docente para la incorporación de laboratorios virtuales en el plan de estudios del master universitario en automática y robótica. XII Jornadas de Redes de Investigación en Docencia Universitaria, Universidad de Alicante. Vicerrectorado de Estudios, Formación y Calidad. Recuperado el día 5 de junio de 2016 de http://rua.ua.es/ dspace/handle/10045/41767\#vpreview

Rivera, N., Agudelo, A., Ramos, X. M., y Vargas, J. C. (2015). Implementación del ABP como método para promover competencias de colaboración en un ambiente virtual (webnode). EDUTEC, Revista Electrónica de Tecnología Educativa, 51. Recuperado el 30 de abril de 2016 de http:// www.edutec.es/revista

Rodríguez-Rivero, Y., Molina-Padrón, V., Martínez-Rodríguez, M., y Molina-Rodríguez, J. (2014). El proceso enseñanzaaprendizaje de la química general con el empleo de laboratorios virtuales. Avances en Ciencias e Ingeniería, 5:(1), 67-79. Recuperado el 17 de junio de 2016 de http:// www.redalyc.org/articulo.oa?id=323630173007

Santillán, C. F. (2006). El Aprendizaje Basado en Problemas como propuesta educativa para las disciplinas económicas y sociales apoyadas en el B-Learning. Revista Iberoamericana de Educación. Centro Universitario de los Valles, Universidad de Guadalajara, México.
Simmons, N. (2013). Outcomes of Learning. Ed. M. Kompf \& P. Denicolo. Critical Issues in Higher Education. Volume 8 of the series Critical Issues in the Future of Learning and Teaching. USA: SensePublishers, 85-96. DOI: 1 94-6209-046-0 7.

Universidad Politécnica de Madrid (2017). Laboratorios Virtuales. Recuperado el día 6 de julio de 2017 de https://3dlabs. upm.es/

Van Oostveen, R., Childs, E., Flynn, K., y Clarkson, J. (2014). Integration of PBL Methodologies into Online Learning Courses and Programs. International Conference e-Learning, 257-362. Revisado el día 18 de junio de 2016, disponible en http://files.eric.ed.gov/fulltext/ED557250. pdf

Vázquez, S. A. (2009). Laboratorios virtuales. Innovación y experiencias, 20(1), 1-11.

Wayne. W., Lin, C., Ho, M., y Wang, J. (2015). Technology Facilitated PBL Pedagogy and its Impact on Nursing Students' Academic Achievement and Critical Thinking Dispositions, The Turkish Online Journal of Educational Technology, 14:(1), 97-107. Recuperado el día 19 de junio de 2016 de http://files.eric.ed.gov/fulltext/EJ1057343.pdf

Whitehurst, J. G., y Lonigan, J. C. (1998). Child Development and Emergent Literacy. Vol. 69(3), 848-872. DOI: $10.2307 / 1132208$.

Yeo, J., y Chee Tan, S. (2014). Redesigning Problem-Based Learning in the Knowledge Creation Paradigm for School Science Learning. Instructional Science: An International Journal of the Learning Sciences, 42:(5), 747-775. Recuperado el día 19 de junio de 2016 de http://link. springer.com/article/10.1007\%2Fs11251-014-9317-6 


\section{Meta-Análisis del Artículo}




\section{Dimensión Cuantitativa}

\section{Perfil de Evaluación entre pares}
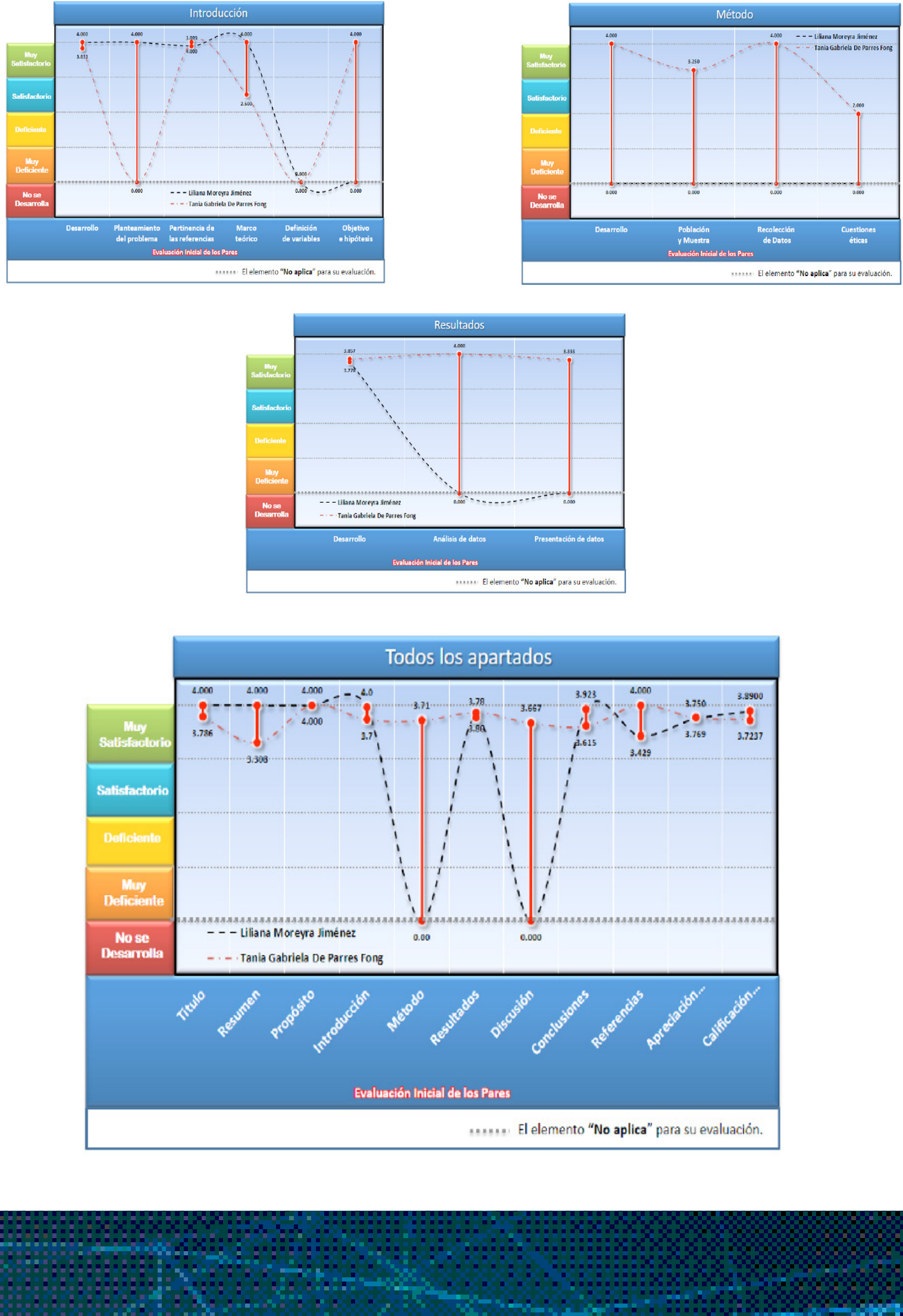


\section{Índice de Concordancia}

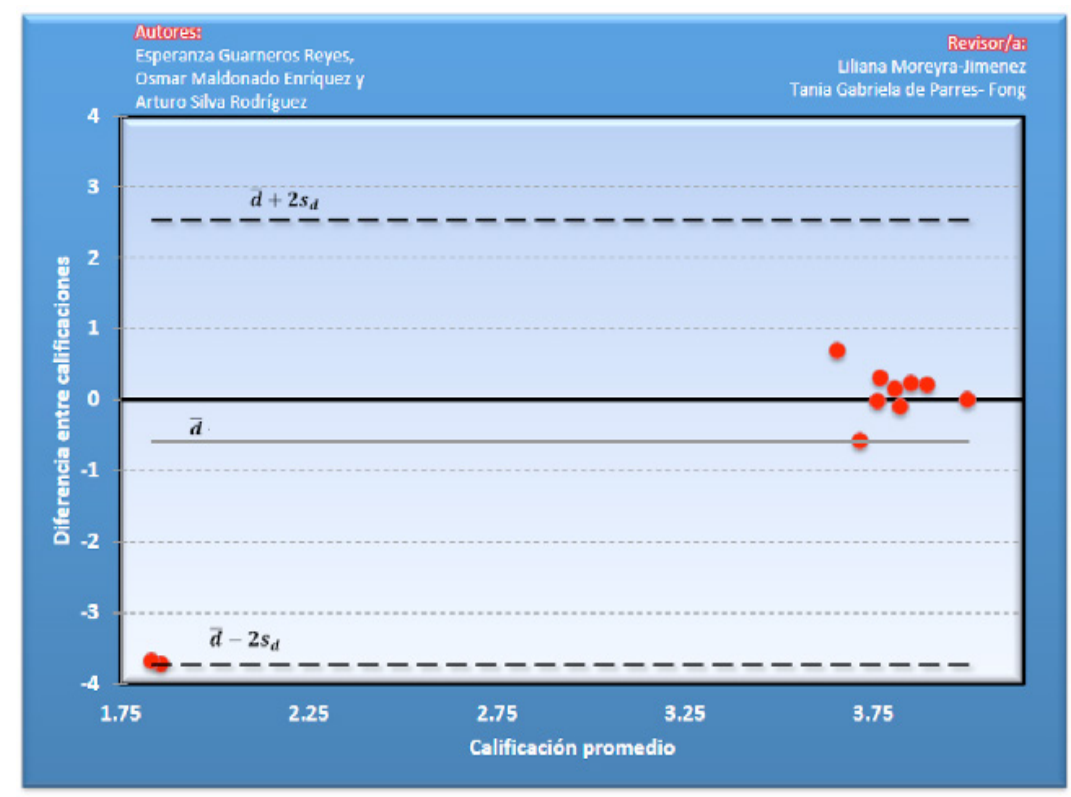

Índice de Acuerdo

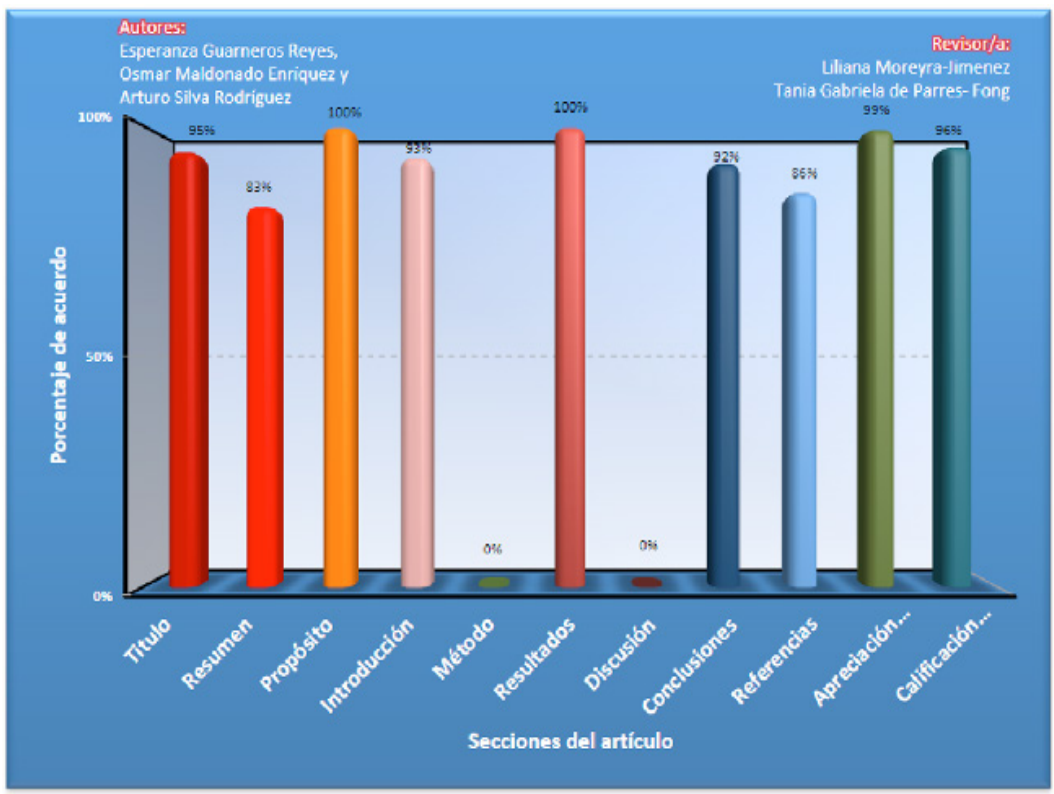




\begin{tabular}{|c|c|}
\hline Revisor 1 & Revisor 2 \\
\hline Liliana Moreyra Jiménez & Tania Gabriela De Parres Fong \\
\hline
\end{tabular}

\section{Título/Autoría}

La sugerencia en el título es iniciar con el nombre de: Laboratorio virtual en psicología; considerar si es pertinente utiliza el concepto de estrategia de enseñanza

Se recomienda incluir la descripción completa de ABP en ABP en lugar de Diseño Instruccional.

\section{Resumen}

La sugerencia es modificar el resumen si se cambia en el concepto de diseño instruccional

Valdría la pena considerar las 150 palabras máximas que debe contener el resumen porque se están excediendo del límite. En la versión en inglés del resumen no se aborda con claridad que la última frase son los resultados.

\section{Próposito del Estudio}

En está sección no existen sugerencias, es adeucado el propósito del estudio.

Al tratarse de una propuesta de un diseño

\section{Introducción}

La sugerencia es revisar las citas que correspondan con el listado de referencias.

Considerar incluir en la introducción información relativa al lenguaje infantil, las habilidades lingüísticas de niños en preescolar y sus problemas en cuanto a cómo se enseña actualmente.

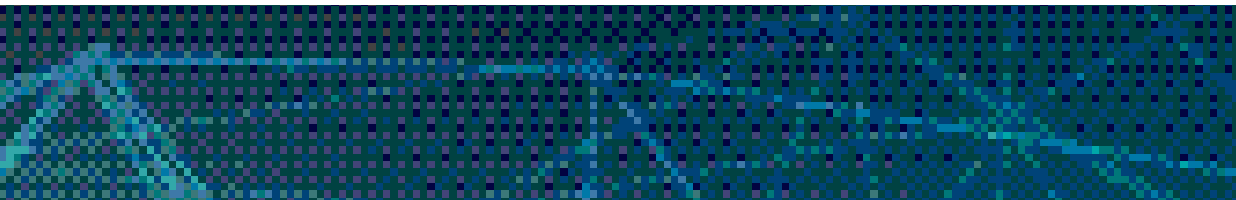




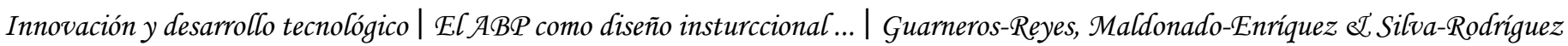

\begin{tabular}{|c|c|}
\hline Revisor 1 & Revisor 2 \\
\hline \multicolumn{2}{|c|}{ Método } \\
\hline No existen Sugerencias. & $\begin{array}{l}\text { Considerar si es necesario incluir el manejo de la confi- } \\
\text { dencialidad de los participantes. }\end{array}$ \\
\hline \multicolumn{2}{|c|}{ Resultados } \\
\hline No existen Sugerencias. & $\begin{array}{l}\text { Es importante también mencionar aquellos aspectos } \\
\text { que pudieron resultar en asociaciones negativas y que } \\
\text { son también útiles para futuras investigaciones o para } \\
\text { ajustes en la propuesta del laboratorio. }\end{array}$ \\
\hline \multicolumn{2}{|c|}{ Discusión } \\
\hline No existen Sugerencias. & $\begin{array}{l}\text { Si contribuyen los tres artículos en los que se aplican } \\
\text { tecnologías basadas en ABP sería prudente incluir los } \\
\text { resultados de los mismos en la conclusión para reforzar } \\
\text { los hallazgos encontrados en la presente } \\
\text { propuesta }\end{array}$ \\
\hline \multicolumn{2}{|c|}{ Conclusiones } \\
\hline No existen Sugerencias. & $\begin{array}{l}\text { Incluir algunas deficiencias detectadas en la propuesta } \\
\text { es de gran valor para futuras investigaciones. }\end{array}$ \\
\hline \multicolumn{2}{|c|}{ Referencias } \\
\hline $\begin{array}{l}\text { Sugerencia: Comparar que las citas aparezcan en el lis- } \\
\text { tado de referencias. }\end{array}$ & Pertinente y suficiente revisión bibliográfica \\
\hline
\end{tabular}


